\title{
AYER Y HOY EN LA DIDÁCTICA DE LA EDUCACIÓN SUPERIOR
}

\author{
María del Pilar Jaramillo Mantilla ${ }^{29}$ \\ «...la escuela ha dejado de ser el único lugar de educación»
}

Guy Avanzini

\section{RESUMEN}

En su primera parte, el artículo plantea un recorrido histórico por los caminos de la didáctica, desde mediados del siglo XVII —cuando Juan Amós Comenio escribe Didáctica Magna, obra fundamental de posteriores desarrollos - hasta nuestros días. Se describe el surgimiento de las primeras escuelas normales para maestros en la Europa de 1800, el posicionamiento de la enseñanza superior a través de las universidades y escuelas superiores, a finales del mismo siglo, y, las condiciones de guerra como generadoras de cambios en la enseñanza del siglo XIX. Es a mediados del siglo xx que la enseñanza técnica se inserta en la educación superior estabilizándose en centros de formación para adultos y certificando la formación.

La segunda parte del texto describe las relaciones teórico-prácticas en la educación a partir de la didáctica, y la manera en que cada tendencia ha comprendido, de forma diversa, dicha relación traducida en actos pedagógicos. Finaliza el siglo xx con la defensa a la ciencia, incluida la didáctica como una ciencia de la educación. Se impone el trabajo individualizado mediado por las máquinas del aprendizaje y la virtualidad, reiterando el compromiso que se establece con la didáctica particular cuando varía la modalidad de la enseñanza y que, para efecto del presente artículo, se centra en la educación superior.

En la última parte se destaca la formación docente como objeto de conocimiento y la docencia como ejercicio innovador y transformador del proceso educativo. Marginalidad, exclusión, construcción del conocimiento, entre otros aspectos, son contemplados en el artículo dejando abierta la reflexión y la crítica para ampliar la mirada y el quehacer de las universidades y de sus actores.

Palabras clave: educación, didáctica, pedagogía, educación superior, enseñanza, aprendizaje.

\begin{abstract}
In its first part the article sets up a historical journey through the paths of didactics, since the mid 17th century - when Juan Amós Comenio writes "Didactica Magna” a fundamental piece

29 Docente vinculada al Proyecto Académico de Investigación y Extensión en Pedagogía (PAIEP) de la Universidad Distrital Francisco José de Caldas. Licenciada en Educación Preescolar, Universidad de San Buenaventura. Magíster en Procesos y Estructuras del Aprendizaje, Universidad Externado de Colombia. Candidata a Doctorado en Psicología Social y Antropología de las Organizaciones, Universidad de Salamanca, España.

El trabajo realizado es descriptivo, presentado cronológicamente. Abarca estudios de didáctica desde el siglo XVII hasta nuestros días y responde al interés del autor por compartir con la comunidad educativa y científica, las reflexiones que desde la experiencia particular y la práctica en docencia universitaria aporten elementos en la construcción del conocimiento. El artículo se concluyó en el año 2009.
\end{abstract}


of further developments in the thematic - until our days. The author describes the surge of the first normal schools for teachers in the 1800's Europe, the positioning of higher education through Universities and Superior Schools, by the end of that very century; and the conditions of war understood as change generators in the 19th century given that those schools reserved for men are then open to women. It is in the mid 20th century that the technical education paves its way in higher education stabilizing itself in professional formation centers for adults and thus certifying professional aptitude.

In the second part, theoretical-practical relations in education based on didactics are described, it is observed the manner in which every tendency has comprehended in a diverse way that relation translated into pedagogical actions. The 20th century finalizes with the defense of science, including didactics among educational sciences. Individual work is imposed mediated by the machines of learning and virtuality reiterating the commitment that its established with particular didactics when the teaching modality changes, and that for this article sake, its centered in higher education.

The last part of the article focuses on the education of docents as knowledge object and docency as an innovative and transforming exercise of the educational process. Marginality, exclusion, knowledge construction, among other concepts, are contemplated in the article leaving reflection and critics open in order to broaden the look and the work of universities and its actors.

Key words: Education, Didactics, Pedagogy, Higher education, teaching, learning.

Recibido: 16 de febrero de 2009

Aceptado: 3 de abril de 2009

\section{UN PANORAMA HISTÓRICO}

Al revisar el devenir histórico de la didáctica se hace necesario sumergirse en el amplio horizonte de la educación; no es posible hablar de esta sin reconocer su inserción en el entramado pedagógico.

Se habla de didáctica como fruto de las reformas del siglo XVII, cuando se menciona igualdad entre hombres y mujeres, entre ricos y pobres y, cuando los individuos, sin distingo de ninguna índole, defienden el acceso a la instrucción y al conocimiento.

La obra más antigua alusiva a la didáctica y publicada en 1657, fue aquella escrita por Jan Amos Komenský ${ }^{30}$ denominada Didáctica magna. En su texto, didáctica se definía como el artificio universal para enseñar todas las cosas a todos, con rapidez, alegría y eficacia. Este autor, apoyado en la teoría luterana, abocó por la educación sin exclusiones. Fue defensor de las ideas pacifistas y conciliador nato lo cual lo hizo merecedor del apelativo de Ángel de

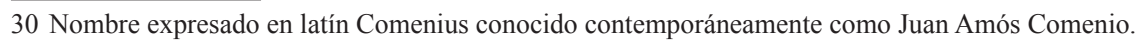


la Paz; propugnó por la abolición de la violencia en la educación en tanto consideraba que con golpes, generalmente, el maestro encubre sus propias deficiencias. Combatió el sistema educativo imperante, al procurar superar las carencias del entorno y de la escuela misma; logró dotar de materiales educativos sus espacios de enseñanza y defender desde la práctica pedagógica, una escuela para todos. Una escuela para mujeres y hombres, para los de escasos recursos y para aquellos con posibilidades económicas, una escuela encaminada hacia la universalización del conocimiento, escuela obligatoria para todos, especialmente la atinente a la primaria.

Comenio, el evangelista checo de 1600, politizado y combatido, vivió la quema de sus manuscritos en medio de un entorno hostil y adverso sin que el miedo fuese para él, argumento de presión laboral o educativo. Estimulaba a los estudiantes a dirigir sus propios pensamientos, lo que hoy se llama conducir su aprendizaje desde la teoría hacia la práctica de vida. Él lo esbozaba como conocer las cosas para luego enseñarlas. Convencido de la necesidad de enseñar desde la más temprana edad y en el idioma materno, se encuentra a Comenio en los albores del respeto a la individualidad. Que aprendan a usar correctamente sus sentidos y reconozcan las causas y las consecuencias, significa la lógica para este estudioso de la didáctica.

El amor por la naturaleza y la sensibilización de las expresiones artísticas estuvo en la mira de sus intereses para la educación de pequeños y adolescentes. Para Juan Amos el aprendizaje debía ser alegre y festivo, como el juego. En la sabiduría de su Didáctica magna se encuentran expresiones como que no se debe enseñar lo que se sabe, sino lo que son capaces de aprender los alumnos. Esto, a la luz de la pedagogía contemporánea significa preguntarse por el estudiante con el cual se interactúa. No sin razón también se le llamó Príncipe de la Instrucción.

Pasados más de cien años el filósofo alemán Jean Fréderic Herbart (1776-1841) se dedicó al estudio de la pedagogía científica apoyado en la psicología; concibió la formación del individuo desde la virtud y la moralidad, siendo la instrucción base de la educación. El punto central de su doctrina fue la libertad interior, lo que hoy se podría interpretar como la generación de seres autónomos, vistos desde la conducta moral muy por encima de lo intelectual o lo social.

Plantea como tendencia fundamental de todo ser la «autoconservación». Concibe al yo como un ser simple que, al autoconservarse, se ofrece en las representaciones, elementos únicos de la vida psíquica. Mantener la propia independencia para la pedagogía es el acierto que permite al individuo conocerse e interactuar con el otro en condiciones de libertad. «El sistema en Herbart se completa con una Ética y una Pedagogía...la idea de la libertad interna, entendida como la concordancia en la relación existente entre la voluntad y la conciencia moral», ${ }^{31}$ es el fin último de la educación herbatiana. El maestro, para este filósofo de la educación, debía ser lo suficientemente carismático y artista como para conducir a los niños y a los adolescentes - a quienes se les venía viendo como seres vacíos- con un manejo como de tabla rasa.

31 Ferrater Mora, José. Diccionario de Filosofia. 3. a edición. Buenos Aires: Editorial Sudamericana. 1951. p. 432. 
A pesar de la distancia en la mirada de la educación tres siglos después, se encuentran concepciones teóricas y actores al interior de los procesos de enseñanza-aprendizaje que parecieran seguir el curso de lo pedagógico en sentido contrario a las manecillas del reloj. Por fortuna la voluntad de cambio es imperante en los nuevos tiempos, y, que antaño se viera al alumno como recipiente no significa que, actualmente, teóricos, teorías y pensamientos filosóficos no lleven inmerso un sentido de cambio.

Si bien la educación hasta el siglo XVII era exclusivamente de tipo confesional e impensable, la formación de otros enseñantes, es decir, laicos, es finalizando el siglo, en 1671, que, en la Francia de la Revolución y bajo los trabajos de Charles Demia fundador de las «pequeñas escuelas», se crea un centro para formación de maestros en Lyon y, en 1687, uno para maestras, con el fin de subsanar la penuria de enseñantes; y en París dirigido por J. B. de La Salle, un centro similar considerado una primera «escuela aneja».

En 1808, bajo el gobierno napoleónico, el decreto Fourcroy prevé la existencia de «clases normales» para la formación de los maestros destinados a enseñar en la escuela primaria. La expresión entrecomillada clases normales citada por G. Avanzini, deviene del latín: norma, regla, y se le atribuye al asesor educativo de María Teresa de Austria, Felbiger, ${ }^{32}$ quien amplió considerablemente los planes de la formación de los maestros, que para entonces era toda una revolución por el hecho mismo de concebir al maestro como el necesitado del aprendizaje a fin de perfeccionar sus conocimientos para transmitirlos posteriormente.

En 1810 se abre en Estrasburgo la primera escuela normal francesa creada bajo la dirección de Lezay-Marnésia colega y amigo de Pestalozzi. ${ }^{33}$ El avance en la legislación de aquel entonces aboga por la formación de maestros competentes como el caso de lo planteado por la Ley Guizot de 1833. Pero «En 1850, a fin de extirpar lo que se creyó fermento socialista en las escuelas normales y conceder a la iglesia nuevamente el papel principal en la enseñanza, la Ley Falloux tuvo como efecto "humillar" sistemáticamente al individuo procedente de esas escuelas (limitación muy seria de programas) haciendo de él más un sujeto que un actor (desarrollo de la instrucción religiosa en detrimento de todas las restantes disciplinas)»». ${ }^{34}$

En 1879 la ley Ferry pensada para el desarrollo de las escuelas normales abre un nuevo horizonte en la formación de los maestros. Lentamente se despeja el paso para la enseñanza superior a través de universidades y escuelas superiores. Para 1896 la burguesía republicana contaba con más de una decena de universidades que tenían facultades de derecho, medicina, ciencias, letras, y teología. Surgen también algunas escuelas militares y unas escuelas superiores técnicas que impartían formación en artes y oficios; para las mujeres se abrieron escuelas superiores de comercio. Apoyados en la legislación se reconocen escuelas veterinarias y

32 Johann Ignaz von Felbiger. Director de Instrucción Pública.

33 Johann Heinrich Pestalozzi. Pedagogo suizo. Podría considerársele como el pionero de la valoración educativa. Educó en los sentidos — tacto, equilibrio, orientación, observación-. Se interesó particularmente por la formación moral y la educación del carácter en los niños.

34 Avanzini, Guy. La pedagogía en el siglo xx. 2.a edición. Madrid: Narcea, S. A. de Ediciones. 1979. p 324 
de agronomía vinculadas a la enseñanza agrícola. Transcurridos tan sólo cincuenta años de lentos pero certeros avances en el desarrollo de la educación y en la formación de los maestros, estalla la Segunda Guerra Mundial y de su mano, por razones fundamentalmente políticas, se suprimen a partir de 1940 algunas normales.

Son las condiciones de guerra las generadoras de cambios en la enseñanza del siglo XIX ya que aquellas escuelas reservadas a los hombres se abren a las mujeres debido a que los caballeros están en los frentes de batalla. A. Prost en L'enseignement en France ${ }^{35}$ señala cómo a partir de 1927 se hicieron clases conjuntas a los dos géneros, y las señoritas desde entonces pueden concursar con los jóvenes para profesores.

Hacia 1949 la enseñanza técnica que abrirá definitivamente el paso a la educación superior se estabiliza en centros de formación profesional para adultos certificándolos en su aptitud profesional; los colegios técnicos titulan en enseñanza industrial; las escuelas normales nacionales de aprendizaje se encargaban de preparar a los maestros hacia el bachillerato técnico con título en Técnico o Superior de Estudios Comerciales; la Escuela Normal Superior de Enseñanza Técnica formaba a los profesores para enseñar en los colegios técnicos y, por último, las escuelas superiores se encargaban de la alta preparación de economistas, ingenieros y comerciantes.

Luego de los atropellos de la guerra y de las luchas libradas en pro de los Derechos Humanos, incluido el derecho a la educación y a la preparación para todos, se llevan a cabo defensas paralelas como la diversidad de lenguas y el respeto por las etnias y la lengua materna. Así es como la UNESCO en 1953 declara que la lengua materna es para cada uno el medio natural de expresión, y que una de las primeras necesidades del individuo es la de desarrollar su capacidad expresiva. Estos hechos fundamentan la formación de docentes en las lenguas nativas de los grupos humanos, lo que lleva implícita la preparación en las didácticas especiales que requerirá, en consecuencia, el aprendizaje.

Para subsanar las distancias entre la formación de la enseñanza técnica concreta y la abstracción con la que se formaban ingenieros o matemáticos, se crearon los institutos universitarios tecnológicos, caracterizándose estos por la brevedad del tiempo en que los programas eran impartidos y por los contenidos francamente resumidos, lo cual, con razón, no fue bien aceptado toda vez que los institutos se convertían en universidades de segunda clase.

En 1966 en la defensa y promoción de las lenguas regionales en Francia, se admite, por ejemplo, la Licenciatura en Lenguas Modernas incluyendo el vasco, el bretón, el catalán, el occitano y posteriormente el corso. Sin embargo, la defensa de la lengua materna en contraposición a las lenguas «oficialmente impuestas» ha sufrido los embates de las contradicciones políticas e ideológicas. Sabido es que el bilingüismo no riñe con el respeto a la lengua nativa, de la misma manera que las religiones predominantes no son obstáculo a la libertad de cultos, de creencias, ni interferentes en los avances que la ciencia y la tecnología generan en la modernidad.

35 Prost, A. L’enseignement en France. De 1800 à 1967. Paris: Colin. 1968. 
También en Francia, en 1968, la «ley de orientación de la enseñanza superior» dota a las universidades de autonomía en lo pedagógico, lo financiero y lo administrativo; establece que los consejos universitarios deberán ser integrados por estudiantes, docentes, investigadores y personal no docente, y que el espíritu que acompañe a la universidad deberá enmarcarse en la pluridisciplinariedad.

Es innegable reconocer la influencia de las ideas filosóficas y pedagógicas europeas en el desarrollo y en la praxis del ejercicio educativo en los países del nuevo mundo. En la América hispanizada, el derecho romano permea la legislación; la lengua impuesta por la conquista y la colonización fue el español, y de las lenguas y dialectos aborígenes quedan vigentes algunos como el náhuatl o azteca, el quiché, el quechua, el aimara, el guaraní y el mapuche, entre otros.

Las reivindicaciones sociales, culturales, políticas y de toda índole que han exigido los hombres y mujeres del mundo a partir de la generación de conciencia con ocasión de la Primera Guerra Mundial, también atañen al campo educativo. Desde la ONU y la UNESCO los países miembros han pretendido mediante protocolos, convenios, acuerdos y tratados el mejoramiento de las condiciones sociales y culturales de los países. Cada uno va ajustando las demandas de la comunidad internacional a sus propios contextos con el fin de garantizar un mejor desarrollo humano.

En su documento «Educación y didáctica», Jean-Marie Besse refiriéndose a los paradigmas didácticos expresa: «Han aparecido así diversos modelos didácticos nuevos que, irreductibles y concurrentes, van de los límites extremos del "libertarismo" a proyectos de carácter neodirectivo, por ejemplo la enseñanza programada, no sin pasar por diversas formas de trabajo en grupo y de pedagogía institucional». ${ }^{36}$

Difícil abarcar la totalidad de movimientos que, a través de la historia de la educación, han sido determinantes en la acción pedagógica contemporánea. Sin embargo, se retoman algunos momentos significativos ya por su concepción, ya por su metodología o didáctica, que han signado el curso del último siglo de la historia de la humanidad y los inicios del presente siglo.

De León Tolstoi se conocen más, sin lugar a duda, sus obras literarias Ana Karenina y La Guerra y la Paz, que su pensamiento pedagógico. En el volumen 13 de sus obras completas se percibe el rechazo al discurso educativo; amante de la duda filosófica y de la libertad dice: «no aceptaremos la filosofía de la educación, ya que no podemos admitir la posibilidad de que un hombre sepa lo que otro tiene necesidad de saber»...«La base de nuestra actividad es la convicción de que no solamente no sabemos, sino que incluso no podemos saber en qué debe consistir la instrucción del pueblo, y en que no solamente no existe ciencia alguna de la instrucción y de la educación - la pedagogía - sino que ni se han planteado aún sus primeros fundamentos; la definición de la pedagogía y su finalidad, en sentido filosófico, es imposible, inútil y perjudicial» en la instrucción pública. En Tolstoi se percibe una escuela no

36 Besse, Jean-Marie. Educación y didáctica. En: Avanzini, Guy. La pedagogía en el siglo xx. 2.a edición. Madrid: Narcea, S. A. de Ediciones. 1979. p. 153. 
clasista y dedicada más a los sectores más desfavorecidos, y se reitera el debate y el sentido del derecho a lo público.

Luego de la experiencia pedagógica de tipo libertario de los maestros-compañeros de Hamburgo de 1920, A. S. Neill ${ }^{37}$ en Inglaterra crea la escuela de Summerhill. Este partidario de la libertad, tildado de anarquista por sus contemporáneos, defiende básicamente el respeto y la no represión, sin embargo, tampoco es defensor del laisser-faire, laissez, en tanto la finalidad educativa en Summerhil es aprender a vivir libremente dentro del respeto a sí mismo y el respeto del otro. Mauco, defensor de Neill y su postura pedagógica, describe la experiencia de este educador como «el más audaz en el rechazo de todas las prohibiciones sin caer en el vacío anarquizante de los libertarios». ${ }^{38}$

Sadoun, Schmidt y Schultz ${ }^{39}$ en Boutiques de Niños describen el movimiento alemán de las Kinderlaeden donde la perspectiva radica en la construcción de una sociedad socialista basada en los principios de una libertad sin represión dentro de una educación autónoma marginal a los padres, en la cual el niño se enfrente a la sociedad de su momento con el objeto de transformarla.

Fachinelli, Murar y Vaiani en la Escuela de lo imposible, refiriéndose a las experiencias antiautoritarias de Italia denuncian la didáctica impositiva en la educación en los siguientes términos: «La didáctica autoritaria desarraiga, reprime y aplasta las exigencias culturales, las inquietudes políticas, las motivaciones instintivas de los alumnos, es decir, los fundamentos todos de la autonomía política, cultural y psicológica de la personalidad social, para implantar en su lugar el conformismo y los valores culturales establecidos»..40

Si bien lo hasta ahora planteado expone la fe en el individuo, en la libertad, en el tratamiento respetuoso y el no autoritarismo, la pedagogía perfila la necesidad de una educación y de una escuela acorde a las necesidades globales, se está apenas en la elaboración de los conceptos que, aunque afinados, no parecen lo suficientemente desarrollados para las exigencias de las didácticas especiales contemporáneas.

37 Se le conoce como el constructor y creador de Summerhill en los suburbios londinenses hacia 1921. Educador y psicoanalista que creyó y confió amorosamente en los niños y en el individuo a pesar del dañó que experiencias nocivas generen en el individuo. Escribió La liberté, pas l'anarchie réflexions sur l'éducation et l'expérience de Summerhill.

38 Mauco, M. La paternité. París: Ed. Universitaires. 1971. p. 142.

39 Sadoun, F.; Schmidt, V,; Schultz, F. Les boutiques d'enfants. París. 1972.

40 Facchinelli, E.; Murar, I.; Vaiani, L. M. ; Sartori, G. L'école de l'IMPOSSIBLE Expérience de pédagogie nonautoritaire. París: Mercure de France. 1972. p. 31. 
Dominique Ginet ${ }^{41}$ en su análisis de la educación nueva reconoce los aportes de la obra pedagógica de E. Durkheim y de John Dewey ${ }^{42}$ destacando en los estudios de Dewey el acto cognitivo como esencialmente motivado por una necesidad práctica, otorgándole lugar principal de su pedagogía a la experiencia ${ }^{43}$ como realidad central, y como intercambio activo entre el sujeto y su entorno, planteando que se aprende por experiencia. En su breve autobiografía, refiriéndose a los motivos que orientaron su pensamiento, está «en primer lugar la importancia otorgada a la teoría y práctica de la educación. En segundo término el deseo de superar el dualismo entre "ciencia" y "moral" por medio de una lógica que sea "un método de investigación efectiva" y que no rompa la continuidad de las diversas regiones de la experiencia. En tercer lugar, la mentada influencia de James. Finalmente, la intuición de la necesidad de una integración del pensar que comprenda los problemas desarrollados por las ciencias sociales y que permita resolver al mismo tiempo las situaciones derivadas de tales problemas. La insistencia en la experiencia sólo adquiere sentido a partir de estas bases»». ${ }^{44}$

Dewey en «Una introducción a la filosofía de la educación» denuncia: «Uno de los más graves problemas que la filosofía de la educación ha de abordar es el método de mantener un equilibrio adecuado entre los modos de educación espontáneos y los sistemáticos, los incidentales y los intencionales. Cuando la adquisición de información y la destreza intelectual no influyen en la formación de una disposición social, la experiencia vital ordinaria no logra adquirir sentido, mientras que la escolaridad sólo crea cultos "ingeniosos", es decir, especialistas egoístas». ${ }^{45}$

Roger Cousinet, educador, psicólogo y catedrático de pedagogía en la Universidad de la Sorbona, y Celestin Freinet, luchador incansable en contra de la escuela tradicional y precursor de la «Escuela del Pueblo» fueron los pioneros de la pedagogía de grupo y centrada en el grupo. Ellos pretendieron sentar las bases de lo que años después serían las dinámicas de grupo; en su momento no lograron hacer realidad sus proyectos pero vale recordar que se debe a Freinet el concepto de autogestión, principio que se fortalecería posteriormente. En su escrito denominado «Basta de manuales», hace reproche de ellos como reflejo de la educación de la época, el saber estrecho, parcializado, dogmático y escolástico.

41 En su texto «el grupo en pedagogía» analiza el trabajo de los precursores de la educación nueva, entre quienes se reconoce a Durkheim, a Dewey y a Celestine Freinet que avalan la interacción entre los individuos en el interior de los grupos.

42 Emilio Durkheim y John Dewey filósofos preocupados por la pedagogía; el primero concibe la educación como función social prioritaria garante del equilibrio de la sociedad y, el segundo, fundador de las escuelas-laboratorios se apoyó en la psicología genética naciente del siglo XIX y defendió la experiencia como el elemento fundamental en el desarrollo de la personalidad de los individuos.

43 José Ferrater Mora en el Diccionario de Filosofía define que experiencia no es para Dewey lo meramente experimentado por un sujeto, y menos lo que este experimenta con el fin de adquirir un saber, sino el resultado de una relación que para el sujeto tiene como término, a la vez opuesto y complementario, el objeto y el medio, pero que puede ser concebida en su mayor generalidad como relación entre objetos, como su forma propia de mantener una conexión.

44 Ferrater. Op. cit. p. 228.

45 Dewey, John. Democracia y educación. Una introducción a la filosofía de la educación. Buenos Aires: Losada. 1946. p. 37. 
Juan Mallart en su texto «Didáctica: concepto, objeto y finalidades» presenta diversas definiciones con respecto a didáctica; sus conceptos y alusiones a algunos de los autores han sido retomados a fin de continuar con el panorama histórico de la didáctica en el entorno educativo, y detectar la evolución del concepto en los últimos cincuenta años.

El maestro y pedagogo español José Fernández Huerta, nacido a principios del siglo xx, considera que la didáctica tiene por objeto las decisiones normativas que llevan al aprendizaje gracias a la ayuda de los métodos de enseñanza. En 1964, enfocó el estudio de la didáctica desde el trabajo docente congruente con los métodos de aprendizaje.

Imídeo Giuseppe Nérici, en 1973, plantea el concepto de didáctica en Hacia una didáctica general dinámica, en términos de: «La didáctica es ciencia y es arte de enseñar. Es ciencia en cuanto investiga y experimenta nuevas técnicas de enseñanza, teniendo como base, principalmente, la biología, la psicología, la sociología y la filosofía. Es arte, cuando establece normas de acción o sugiere formas de comportamiento didáctico basándose en los datos científicos y empíricos de la educación; esto sucede porque la didáctica no puede separar teoría y práctica. Ambas deben fundirse en un solo cuerpo, procurando la mayor eficiencia de la enseñanza y su mejor ajuste a las realidades humana y social del educando. De un modo más explícito, puede decirse que la didáctica está representada por el conjunto de técnicas a través de las cuales se realiza la enseñanza; para ello reúne y coordina, con sentido práctico, todas las conclusiones y resultados a que arriban las ciencias de la educación, a fin de que dicha enseñanza resulte más eficaz. La didáctica es una disciplina orientada en mayor grado hacia la práctica, toda vez que su objetivo primordial es orientar la enseñanza». ${ }^{46}$

Escudero $^{47}$ en 1980 insiste en el proceso de enseñanza-aprendizaje como ciencia que tiene por objeto la organización y orientación de situaciones de carácter instructivo, tendientes a la formación del individuo y, en estrecha dependencia de su educación integral.

Quien le otorga a la didáctica un carácter eminentemente científico es Gimeno Sacristán ${ }^{48}$ en 1981, al considerarla como una disciplina a la que corresponde guiar la enseñanza, que tiene un componente normativo importante en forma de saber tecnológico y que pretende formular recomendaciones para guiar la acción y el orden dentro del mismo accionar.

El profesor Miguel A. Zabalza, ${ }^{49}$ en 1987 define la didáctica como el campo de conocimiento, de investigaciones, de propuestas teóricas y prácticas que se centran, sobre todo, en los procesos de enseñanza y aprendizaje.

46 Nérici, Imídeo Giuseppe. Hacia una didáctica general dinámica. Buenos Aires: Editorial Kapeluz. 1973. p. 54.

47 Escudero, Juan Manuel. Inovação e Formação Centrada na Escola. Uma Perspectiva da Realidade Espanhola, en A. Amiguihno y R. Canário (Organiz.): Escolas e Mudança: O Papel dos Centros de Formação. Lisboa: Educa.

48 Pedagógicamente se inscribe en la línea del desarrollo cognitivo preconizado por Jean Piaget y Lev Vigotsky, línea que trabaja por un paradigma del docente investigador crítico que realce el papel del proceso educativo más allá de los resultados finales.

49 Miguel A. Zabalza Beraza, psicólogo y pedagogo de reconocida trayectoria en el ámbito educativo hispanoamericano. 
Otro pedagogo que también apoya el carácter científico de la didáctica es Benedito ${ }^{50}$ (1987) quien en Introducción a la didáctica. Fundamentación teórica y diseño curricular, se refiere a que está en camino de ser una ciencia y una tecnología que se construyen desde la teoría y la práctica, en ambientes organizados de relación y comunicación intencional, donde se desarrollan procesos de enseñanza y aprendizaje para la formación del alumno.

Juan Mallart en el año 2000 define la didáctica como la ciencia de la educación que estudia e interviene en el proceso de enseñanza-aprendizaje con el fin de conseguir la formación intelectual del educando. Considera que la didáctica debería ocuparse de los procesos que tienen lugar en un contexto curricular o institucional. El autor piensa si vale la pena preguntarse cuán diversos serán los procesos planteados o diseñados pertinentemente a cada uno de los espacios curriculares o institucionales.

De manera particular, este autor reflexiona sobre la enseñanza, la cual es, al mismo tiempo, una actividad práctica, y hace énfasis en la importancia de combinar adecuadamente el saber didáctico, es decir, «la teoría» con el hacer didáctico correspondiente a «la práctica» dando lugar al «acto didáctico» propiamente dicho. Justamente esa combinación responde a las características ideales de un equilibrado ejercicio educativo. Destaca el valor de la práctica de la enseñanza en cuanto esta se halla presente en todas las actividades de los alumnos y en las de los profesores.

En concordancia con Mallart, quien cree que la didáctica va más allá del aula, de los espacios institucionales y del entorno tradicional dedicado a la enseñanza, se piensa, por tanto, que existen distintos espacios, y diversas formas de aprendizaje. Así por ejemplo, tendríamos un aprendizaje desde el punto de vista de lo cronológico, desde lo meramente espacial, desde el individuo o el colectivo y los grupos que aprenden, o desde la forma en que la transmisión se realiza, etc. El mismo autor concibe la didáctica como un proceso donde uno es quien aprende y otro es quien enseña.

Posteriormente Zabalza en 2004, refiriéndose al uso de los materiales didácticos para propiciar aprendizajes autónomos plantea que es preciso reconstruir la propia disciplina poniéndose en el lugar del alumno, y recientemente, en Las competencias docentes del profesorado universitario. Calidad y desarrollo profesional, señala la importancia de la misión formativa institucional universitaria que se concreta y operativiza en la oferta curricular, y recalca cómo la calidad de la formación depende, especialmente, de la actuación del profesorado.

\section{LAS RELACIONES TEÓRICO PRÁCTICAS EN LA EDUCACIÓN A PARTIR DE LA DIDÁCTICA}

Shirley Grundy en su texto Producto o praxis del currículum, considera el desarrollo de los programas curriculares entendido desde la didáctica como una forma de praxis o acción práctica donde los elementos constitutivos de la praxis son la acción y la reflexión. La praxis

50 Benedito, Vicenç. Aproximación a la didáctica. Barcelona: PPU. 1986. 
tiene lugar en el mundo real, no en el hipotético y esta praxis se hace efectiva en el mundo de la interacción, el mundo social y el cultural. Por tanto el mundo de la praxis es el construido, no el mundo natural. La praxis supone un proceso de construcción de significados, reconociendo este proceso como construcción social.

Juan Mallart, destaca el planteamiento del profesor Zabalza Beraza, quien considera que en didáctica se ha venido actuando de acuerdo con el esquema teoría-práctica-teoría prevaleciendo un modelo de aproximación a la realidad en el cual predominan los discursos teóricos y nominalistas basados más en creencias que en datos contrastados.

Mallart propone pasar por el esquema práctica-teoría-práctica ya que esta estructura supera a la anterior porque «la teoría se acomoda más a las condiciones de la práctica, surge como elaboración justificada a partir del estudio de las prácticas y condicionada por las características y variables, por la complejidad que caracteriza esas prácticas» (Zabalza, en Introducción a de la Torre, ${ }^{51}$ 1993). Sin partir de la práctica tendremos pocas posibilidades de poder incidir sobre ella para cambiarla.

El autor plantea que existe una «Teoría de la enseñanza» diferenciada de una «Teoría del aprendizaje», pero en estrecha relación con ella. La teoría de la enseñanza no puede caer en una pura aplicación de la praxis de decisiones normativas procedentes de otras disciplinas o del mismo sentido común. Ahora bien, si esta teoría de la enseñanza parte de la práctica real y se integra a la teoría del aprendizaje, puede servir para explicar el proceso de enseñanza-aprendizaje, y ordenar la acción de la misma enseñanza.

Viviana Macchiarola ${ }^{52}$ y otros, en su documento de trabajo titulado «La compleja vinculación teoría-práctica en tendencias de formación docente» analizan lo sucedido en los últimos cincuenta años de práctica pedagógica a la luz de diversos marcos epistemológicos, sociales, psicológicos y pedagógicos, expresando a su vez, los procesos formativos que generan las diferentes tendencias. Plantean, sorprendentemente, de qué manera el curso de los acontecimientos en el desarrollo de las relaciones entre teoría y práctica pedagógica puede sucederse de forma análoga en contextos variados. Esto se entiende a la luz de las transformaciones y de las imposiciones que la moda (incluida la pedagógica) impone en el desarrollo de la globalización.

Denotan que en los años sesenta el predominio fue de las corrientes llamadas del desarrollo y del capital humano que enfatizaban en los aspectos cuantitativos de los sistemas educacionales, generadores de un modelo de formación docente tecnicista. En la década de los años setenta el paradigma de desarrollo planteado reclama una formación más integradora respecto a la relación sujetos-sociedad. Sin embargo, la práctica educativa tecnicista en la preparación de educadores continuará y se mantendrá desde los años ochenta hasta la actualidad. La línea tecnicista, aunada a las reformas educativas, se refleja en la concepción curricular, y, en el

51 TORRE, Saturnino de la. Didáctica y currículo. Bases y componentes del proceso formativo. Madrid: Dykinson. 1993.

52 MACCHIAROLA, Viviana; MORALES, Gladys; NICOLETTI, Silvia; VOGLIOTTI, Ana. La compleja vinculación teoría-práctica en tendencias de formación docente. Secyt. UNRC. 
perfil de los educadores donde la teoría se impone a la práctica del docente, se minimiza la labor, se atomiza el proceso de enseñanza y se desconoce la complejidad de la vida en el interior del aula.

A finales de la década de los setenta y a comienzos de la de los ochenta surgen perspectivas educativas alternas, a partir de marcos teórico-metodológicos de corte cualitativo, donde adquiere una particular relevancia una perspectiva denominada «constructivista» por su concepción acerca del conocimiento y por el proceso que realizan los sujetos para su apropiación. Caracterizada por la fundamentación psicológica, diferencia en una primera etapa los aportes de la psicogenética piagetiana que delimita la función de la educación al favorecer los procesos constructivos de los sujetos que aprenden, considerando especialmente sus estructuras cognitivas.

Y, en una segunda etapa, con la inclusión de otras perspectivas, como la teoría de la asimilación de Ausubel ${ }^{53}$ y la teoría socio-cultural de Vigotsky ${ }^{54}$ — donde se resignifica la importancia del contenido, es decir, los objetos de conocimiento en los procesos de enseñanza-aprendizajese rescata la verdadera función de enseñanza en el educador ya que su función no está dada sólo en la creación de contextos situacionales para que el alumno construya sus conocimientos, sino que debe conducir el acto educativo hacia la construcción conjunta del saber.

La tercera etapa se conoce como crítico-reflexiva, lleva impresa, como su nombre lo indica, la criticidad, la innovación, y el sello de «profesores como investigadores en la acción» cuyos representantes más significativos son Stenhouse ${ }^{55}$ (1987), Elliot (1990) y Schön ${ }^{56}$ (1987). La reflexión acerca de las prácticas colectivas y de grupo orientadas hacia la constitución de un rol docente como coordinador del aprendizaje, ha sido avalada por Ezcurra et al. (1990) y por González Cuberes (1991); y, la tendencia de «profesores como prácticos reflexivos»o «intelectuales transformativos» ha sido expuesta por teóricos como Carr y Kemmis (1983),

53 David Paul Ausubel y Jerome Bruner son reconocidos por sus aportes en las teorías del aprendizaje significativo como construcción mental dentro de las múltiples posibilidades de adquirir el conocimiento, de transformarlo y de reconstruirlo.

54 Lev Vigotsky, el Mozart de la psicología, es reconocido como el psicólogo y el neuropsicólogo de mayor influencia en la década de los sesenta.

55 Promueve un papel activo de los docentes en las áreas investigativas y curriculares de la educación. Destaca la importancia de la evaluación en el interior de los procesos pedagógicos, superando la mirada de un docente calificador y capaz de valorar la subjetividad y las particularidades de los individuos y de los contextos.

56 Carr, Kemmis y Schön, reconocidos pensadores de la crítica pedagógica y de la investigación educativa, defensores de acción y la reflexión como partes fundamentales del desarrollo investigativo. 
Liston y Zeichner ${ }^{57}$ (1993) e incluso Giroux ${ }^{58}$ en 1990. Partícula integradora de estos tres enfoques en la formación, es la interacción entre la teoría y la práctica que se vinculan a la reflexión del quehacer docente y la relación dialéctica que demanda nuevas miradas y conceptualizaciones que modifican, cambian y enriquecen, de manera permanente, la práctica misma de la acción pedagógica.

Teoría y práctica son componentes necesarios del conocimiento. La intervención que se hace en el interior de estos componentes, y la investigación en y sobre la acción educativa determinan la coherencia de la acción misma.

La formación docente se constituye por sí en objeto de conocimiento; esto es, no sólo se conoce un objeto diferenciado del sujeto sobre el que se ejerce la docencia, sino también el modo como es conocido, allí radica el principio de reflexionar sobre la propia práctica docente como un ejercicio innovador y transformador de proceso educativo.

Concluyendo, y luego de este breve recorrido por la historia de la didáctica en el marco de la educación, y del análisis de las relaciones teórico-prácticas en la educación superior a partir de la didáctica, se vislumbra de qué manera cada tendencia ha comprendido de forma diversa la relación entre la teoría y la práctica, y entre el pensamiento y los actos pedagógicos. Finaliza el siglo xx con la defensa a la ciencia, incluida la didáctica como una ciencia de la educación. Se impone el llamado trabajo individualizado, trabajo que si bien procura la máxima responsabilidad del educando, se cree que lo abandona a su suerte en medio de las máquinas del aprendizaje como son los computadores y la virtualidad.

El trabajo individualizado, como técnica aporta fundamentalmente información, pero no constituye una didáctica atractiva ni interesante. Requiere un maestro exigente que planea y programa desde la ausencia pero que no está en la construcción conjunta, propiamente dicha, del saber, ya que esa construcción está mediada por distancias más allá de lo temporal y lo espacial. No se pretende con esto desvirtuar las múltiples ventajas que acompañan los procesos de aprendizaje en la posmodernidad, muy por el contrario, si bien cada disciplina construye su propio lenguaje para el objeto de estudio que le pertenece, y una didáctica que se ajusta a sus particularidades, todos estos aspectos no se comportan de manera aislada en el campo del saber y no dejan de incidir en la totalidad de las relaciones que la ciencia establece para la apropiación y construcción del conocimiento. El propósito es más con la intención de reiterar el compromiso que se establece con la didáctica particular cuando varía la modalidad de la enseñanza y que, para el presente artículo, se dirige a la educación superior.

57 LISTON, D. y ZEICHNER, K. Formación del profesorado y condiciones sociales de escolarización. Madrid: Morata. 1993.

Describen el trabajo en contextos universitarios, la democratización escolar y la práctica reconstruccionista social en la formación del profesorado, en relación con las desigualdades sociales al margen del género, la raza o la clase social. A partir de sus experiencias como docentes en Norteamérica pretenden mejorar los programas de formación docente y las condiciones de la escolarización en su país.

58 Henry Giroux propende por la formación del educador intelectual transformativo para que luego pueda desarrollar un pensamiento crítico y reflexivo en sus estudiantes. 
Cuando se pregunta ¿qué?, ¿cómo?, ¿cuándo?, ¿para qué? y ¿para quién? enseñar, de manera implícita se deberá ser coherente con las posturas epistemológicas del conocimiento específico que se va enseñar y a aprender, con la didáctica y la transformación que ella connota, $y$, pertinente al entorno que permiten y promueven los procesos de aprendizaje. Una didáctica y una práctica que no se ajuste a tales apreciaciones, difícilmente se adecuará a la construcción y a la comprensión del acto educativo.

Temas como la desescolarización, la educación a distancia, la virtualidad y las nuevas tecnologías requieren, como ya se ha dicho, de didácticas especiales. Este debate cobra vigencia justamente por las distancias del acceso a la educación y a las formas más avanzadas de la ciencia y del desarrollo tecnológico, en contraposición a quienes aún entrado el siglo XXI hacen parte de los millones de iletrados del mundo.

Una variada gama de especialistas de diversas disciplinas y de la educación apoyan los procesos educativos en la actualidad, con la intención de superar no sólo la crisis de la educación contemporánea sino de hacer de los ámbitos educativos espacios de reflexión interdisciplinar donde la calidad de la educación y la solución de los grandes conflictos humanos tengan un espacio de encuentro y de análisis que procuren un devenir acorde al vasto recorrido de la humanidad.

Aquello que sucede en elámbito educativo continúa siendo objeto de estudio y de investigación, fuente del saber y de la construcción colectiva de gran valor, entendiendo que el aula va más allá de los espacios que le fueron históricamente asignados. Se hace imprescindible señalar que la interpretación histórico-cultural de la didáctica y su vinculación con la epistemología, el lenguaje y el discurso deberán conformar un entramado complejo e integral a fin de hacer del acto educativo un todo coherente y significativo para el aprendizaje humano.

\section{UNA MIRADA A LA DIDÁCTICA EN LA EDUCACIÓN SUPERIOR, DESDE LA REFLEXIÓN Y LA CRÍTICA}

Adentrarse en el terreno de la didáctica, en su dimensión y complejidad, con objeto de clarificar su ejercicio, implica penetrar en sus raíces, es decir, enmarcarse en el concepto de la educación.

Resulta indispensable realizar una búsqueda exhaustiva a partir de diversos materiales de apoyo, para profundizar en un objeto de estudio, por ejemplo, desde la elaboración de mapas conceptuales o categoriales que proporcionan lógica y claridad a un asunto propuesto, o hacer revisiones bibliográficas o, trabajar desde la fuente misma del ejercicio pedagógico, para descubrir los móviles de un quehacer particular, como puede ser el del docente en su labor cotidiana. Se considera interesante, entonces, profundizar en las disciplinas que estudian y atienden el vasto mundo de lo pedagógico, medio en el que se desarrollan los actores de la relación enseñanza-aprendizaje.

La tarea, pues, se centra en reflexionar acerca del interrogante fundamental de la educación. Sobre qué se cuestiona, sobre su objeto de estudio, qué es ese mundo, en quiénes lo 
conforman, y en comprender cómo se desarrolla; interrogantes más que afirmaciones que se soportan en los hechos mismos y en la realidad del constructo para entender y orientar la instrumentalización de la educación en el momento actual.

Escuelas, tendencias, doctrinas a través de la historia de la humanidad han descrito cambios continuos en la educación; desde sutiles y grandes transformaciones en la práctica pedagógica como imposiciones y radicalismos obsoletos, hasta verdaderos movimientos reivindicatorios tales como el derecho a la educación, a su universalización o a la gratuidad en su acceso. Cambios en los enfoques filosóficos, en lo propiamente pedagógico, en las metodologías que influyen y transforman a la comunidad educativa han sido la constante que determina el comportamiento humano frente al ejercicio que lo impulsa a cuestionar, innovar, crear, replantear, más allá de la finalidad misma de la educación, de la enseñanza.

Es ejercicio ascendente, en tanto la transmisión de la cultura procura justamente el mejoramiento de las condiciones educacionales. Se piensa en términos de valor en el ejercicio constructivo del hombre hacia los otros seres, individuos, animales, y entorno. Es así como la mirada educativa de hoy se fija también en la naturaleza que nos contiene, en los animales y las plantas; «eduque a su mascota», «no contamine el agua» o «reforeste» serían expresiones inimaginables siglos atrás cuando la depredación de la naturaleza pasaba desapercibida o no se cuestionaba.

Hoy estamos obligados a abolir adagios tales como «la letra con sangre entra» o «loro viejo no aprende a hablar» referido este último no propiamente a los animales sino a los humanos. Los entrecomillados, más allá de expresiones son realidades, hechos comunes que continúan arraigándose en la barbarie de quienes no tienen acceso a la educación por la insuficiencia de la cobertura educativa, porque la escuela ha sido expulsora más que contenedora o porque, como consecuencia de las condiciones de extrema pobreza de la escuela, se deserta por todo tipo de carencias y obstáculos que impiden la permanencia en el interior de la estructura educativa, entre muchas otras razones.

En tanto el sistema educativo se erija al margen de la diversidad o de la marginalidad, es decir, excluyente, será inoperante para los grandes grupos minoritarios. La enseñanza continúa pensándose desde el buró y no desde el aula, la cotidianeidad o desde la realidad y la vida. La escuela, espacio propio del quehacer educativo, desconoce a su alumno; la distancia entre él y el aula, sea de la escuela o de la universidad, garantiza el fracaso escolar, la deserción, la condición de repitiente y la insatisfacción de los estudiantes en general. Lo desconoce porque no tiene en cuenta el saber del niño, del adolescente o del adulto - saber con el que accede a la «educación» ${ }^{59}$ — tampoco su procedencia, sus necesidades, sus intereses ni sus particularidades. Es el estudiante quien se ajusta o no al modelo instaurado y, poco cuenta su bagaje.

59 Como si esta se sucediera exclusivamente en espacios definidos para un acto que, connatural al hombre, ha ejercido desde siempre como ser que aprende. No en espacios predeterminados ni regularizados exclusivamente con el objeto de darse al proceso de educar. 
Reconocer pues, quién es ese niño, joven o universitario con quien se interactúa es el punto de partida de un adecuado proceso de construcción conjunta de conocimiento. Significa aproximarse, de manera respetuosa, a una creación común de posibilidades donde cada uno de los actores establece un vínculo que le es significativo y con el cual va comprometiéndose y descubriendo reales sentidos de vida, de pertenencia, de crecimiento y profesionalización.

Apoyado en la misión y la visión de cada institución educativa, el educador, acorde a sus obras y a su compromiso, es quien se realiza en esa construcción-transmisión del saber respaldado sea bien por una praxis, una sólida formación o un engranaje a un proyecto vinculante.

Esperable, por tanto, la claridad del docente por predeterminar qué va a ser enseñado y cómo será enseñado, transmitido o construido el objeto de estudio, definición llana de didáctica. Si didáctica es el arte de enseñar, ¿con qué arte se está enseñando? ¿Se conoce el objeto de estudio y, más aún, a los sujetos de estudio? ¿Cómo se conduce el aprendizaje ${ }^{60}$ de estos?

Está claro que el hombre aprende en la experiencia y no sólo en la regularización de momentos o espacios dedicados, de manera imperativa, al desarrollo de la educación. Si bien es cierto que es en la academia donde el individuo puede cualificar, profundizar o determinar su saber deseado, en el caso particular de la educación superior, no siempre hallamos la correspondencia entre lo pretendido y lo encontrado. No es frecuente encontrar altos niveles de gratificación entre aquello que es el ideal pedagógico, o los imaginarios de la formación adulta, y lo que verdaderamente se les ofrece en la formación específica expresada en la planeación curricular, particularmente, cuando se confronta con el ejercicio real en el interior de la vida laboral.

La didáctica determina la eficacia del aprendizaje, y el conocimiento dado se transforma en conocimiento aprendido, a su vez aprehendido. Fundamental es, entonces, entender el carácter de técnica, de tecnología en el sentido etimológico que supone toda didáctica. $\mathrm{Al}$ orden de la ciencia le corresponde una evaluación desde su carácter, un objeto de estudio y una instrumentalización propia.

Este es el contexto de la interrogación que se le formula a la pedagogía y a las ciencias de la educación. A la didáctica le corresponde resolver los interrogantes propios de una instrumentalización y de un orden técnico y tecnológico, donde se dan serios procesos de reducción, abstracción $\mathrm{y}$, fundamentalmente, de apropiación y aplicación práctica del conocimiento y de los contenidos singulares de un objeto de estudio específico.

Se debe hacer el acento, para el caso de la educación superior, en el fenómeno que se da al singularizar y reducir el objeto de estudio de la enseñanza, de tal manera que implique una didáctica particular y específica al contenido igualmente específico y particular.

60 La enseñanza, en los más elementales términos, es la dirección, la conducción del aprendizaje. 
Es connatural a la educación superior ofrecer al joven adulto profundizar conocimientos en un objeto de estudio limitado, en una ciencia o arte específico. Al avanzar en el proceso de enseñanza-aprendizaje a los universitarios postgraduados se les ofrece, particularmente a través de especializaciones, una reducción de conocimientos que profundizan en unos contenidos cada vez más específicos. Por otra vía, las maestrías y doctorados pretenden el ejercicio de un análisis que amplíe los objetos de estudio con un mayor grado de profundidad.

La pregunta que exige el ahora es ¿qué pedagogía y qué didáctica corresponde formular y desarrollar en cada uno de los momentos señalados y para cada una de las necesidades indicadas?

La primera respuesta que se devela de una manera espontánea, es que no existen ni una didáctica ideal ni una pedagogía ideal para todos y cada uno de los momentos y de las necesidades que supone la construcción del conocimiento, conocimientos específicos exigen tecnologías específicas. Se quiere decir con esto didácticas o pedagogías singulares. Es, entonces, cuando cabe preguntarse ¿qué didácticas y pedagogías singulares cualifican la calidad de la educación superior? Indiscutiblemente las que reconocen al individuo como el centro constructor del conocimiento.

Los procesos de pensamiento son procesos que exigen la reelaboración del conocimiento en la mente humana. Pedagogía y didáctica deben exigirse a sí mismas el trabajo de reformular y resignificar el conocimiento en la mente del sujeto que aprende; la didáctica no se centra ni se detiene en el maestro, existe y vive en el sujeto que aprende.

La didáctica, como toda tecnología, se califica y soporta en términos de la eficacia demostrada y, ¿qué tipo de eficacia?, fundamentalmente una eficacia metodológica. ¿Cuál será, entonces, esa eficacia metodológica, aquella que establezca el lazo vinculante entre la oferta de un conocimiento específico y la resignificación de un conocimiento aprendido? ¿A quién le corresponde evaluar esa eficacia? Por supuesto que a toda la comunidad educativa, pero es el estudiante, ese reconstructor de conocimiento, a quien le corresponde principalmente la tarea de validar la recepción de esa oferta educativa.

De manera análoga como al ciudadano le corresponde definir y determinar una transcursividad política a través de la democracia participativa pero, de manera incoherente, no se le ha formado para esa participación, ejercicio de gran complejidad y responsabilidad, al estudiante, quien es el centro del aprendizaje, el núcleo de la comunidad educativa, le corresponde calificar y validar el desarrollo del proceso pedagógico ejercido y manifiesto en su propio aprendizaje, a este estudiante no se le ha formado en el ejercicio también complejo y de profundas implicaciones éticas de evaluarse a sí mismo, a sus condiscípulos, a su currículo, a sus maestros, a su universidad, a su academia.

En la medida en que se desarrolle este proceso responsablemente, se hará del núcleo de la educación un centro operante de la misma al fortalecer todo el universo educativo desde la práctica, desde la experiencia, desde el acontecimiento y el hecho mismo. 
En consecuencia es válido pensar de nuevo al educador desde la pedagogía y la didáctica, volver a los orígenes y retornar gozosos descubriendo y recuperando la ética ${ }^{61}$ del acto educativo.

Sólo individuos más responsables y participativos construyen mejores sociedades. Sólo mejores estudiantes y más comprometidos sujetos que aprenden construyen verdaderos escenarios de academia y aprendizaje, básicamente, universidades decididamente entregadas por una opción humanista y comprometidas en el desarrollo humano integral.

Los valores de la modernidad, expresados en el valor de una ciencia dada deben adaptarse, servirse y nutrirse de las experiencias del desarrollo humano y de las opciones de la universalidad. Una universidad ética, inspirada en el pensamiento de formar al hombre y servir a la sociedad, fortalece sus intenciones al desarrollar de manera vital y humanista un proyecto pedagógico coherente, complejo y profundo que entienda la historicidad del conocimiento, la dinámica del cambio y la fuerza de la singularidad, la diferencia, la pluralidad.

Una propuesta pedagógica que aporte al desarrollo docente debe entender la complejidad de todos los sistemas científicos, metodológicos y tecnológicos que abarca, y para ser funcional y viable debe ser concertada por todos los actores sociales que integran la comunidad educativa.

La universidad, como centro de la educación superior y responsable de un desarrollo humano integral, debe ampliar su mirada y su quehacer fundada en la dignidad y la responsabilidad de los individuos que la constituyen — que no son de manera excluyente quienes la lideran—, es decir, en el verdadero valor de la comunidad de todos aquellos hombres y mujeres que la componen.

\section{REFERENCIAS BIBLIOGRÁFICAS}

ALEN, B. y Delgadillo, C. Capacitación docente: Aportes para su didáctica. Tesis-Grupo Buenos Aires: Editorial Norma. 1994.

ÁLVAREZ MÉNDEZ, J. M. Entender la didáctica, entender el currículum. Madrid: Miño y Dávila. 2001.

ANGULO RASCO, J. F. La evaluación del sistema educativo: algunas respuestas críticas al porqué y al cómo. Volver a pensar la educación. Madrid: Ed. Morata. Vol. II. 1995.

APPLE, M. y King, N. ¿Qué enseñan las escuelas? En J. Gimeno Sacristán y A. Pérez Gómez, La enseñanza, su teoría y su práctica. Madrid: Akal. 1985.

ARENDT, Hannah. La condición humana. Barcelona: Paidós. 1993.

61 Ética en y desde la educación asumida por teóricos y prácticos de una mirada libertaria como encontramos en Paulo Freire, esperanzadora en Hanna Arendt, o como acontecimiento ético en Fernando Bárcena o Joan Carles Mélich. 
AUSUBEL, D.; NOVAK J.; HANESIAN H. Psicología Educativa. México: Trillas. 1986.

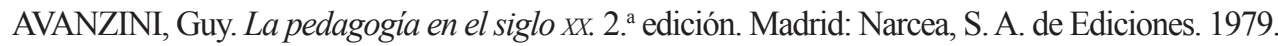

BÁRCENA, Fernando y MÉLICH, Joan Carles. La educación como acontecimiento ético. Natalidad, narración y hospitalidad. Barcelona: Paidós. 2000.

BAUDOUIN CH., Tolstoï. L'éducateur, Neuchâtel: Delachaux. 1921.

BUENO MOREAL, M. J. «Influencia y repercusión de las nuevas tecnologías de la información y de la comunicación en la educación». Bordon, Sociedad Española de Pedagogía. Vol. 48. nro. 3. 1996.

CANDELA, Antonia. Ciencia en el Aula. Los alumnos entre la argumentación y el consenso. Ciudad de México, México: Ed. Paidós. 1999.

CASTORINA. Aprendizaje de la ciencia: constructivismo social y eliminación de los procesos cognitivos. En: Revista Perfiles Educativos de la Universidad Nacional Autónoma de México, Vol. xx, nro. 82. 1998.

CARR, W. y KEMMIS S. Teoría crítica de la enseñanza. La investigación-acción en la formación del profesorado. Barcelona: Martínez Roca. 1988.

COLL, C. Aprendizaje escolar y construcción del conocimiento. Barcelona: Paidós. 1990.

COMENIO, Juan Amos. Didáctica magna. Río de Janeiro: Organizaçao Simoes, Coleçao Mosaico.

CHEVELARD, Y. La transposición didáctica. Barcelona, España: Ediciones Aprendizaje Visor. 1985.

DE SALVADOR GONZALEZ, X. Sobre la evaluación de la actividad docente del profesorado universitario: ¿está mediatizada la valoración de los alumnos por las calificaciones? Revista Española de Pedagogía. nro. 203. 1995.

DEWEY, John. Democracia y educación. Una introducción a la filosofía de la educación. Buenos Aires: Losada. 1946,

ELLIOT, J. La investigación-acción en educación. Morata: Madrid.

ESCURRA, A.; C. De LELLA y P. KROTCH. Formación docente e innovación educativa. Buenos Aires: Grupo editor. 1990.

ETXEBERRIA, F. Política educativa de la Unión Europea: evolución reciente y perspectivas de futuro. Revista Española de Pedagogía. nro. 204. 1996. 
FERRATER MORA, José. Diccionario de Filosofia. 3. a edición. Buenos Aires: Editorial Sudamericana. 1951.

FLÓREZ, Rafael. Hacia una pedagogía del conocimiento. Santa Fe de Bogotá: McGraw-Hill. 2000.

FREIRE, Paulo. Pedagogía de la Autonomía. Madrid, España: Siglo xxi Editores. 1998.

FREIRE, Paulo. Pedagogía de la Esperanza. México: Siglo xxi Editores. 1999.

FUENTES, H. Modelo holístico configuracional de la didáctica de la educación superior. Santiago de Cuba: Centro de Estudios de Educación Superior Manuel F. Gran. Universidad de Oriente. 1998.

GADAMER, H. Verdad y método II. Salamanca, España: Ed. Sígueme. 1994.

GIROUX, H. Los profesores como intelectuales: hacia una pedagogía crítica del aprendizaje. Barcelona: Paidós. 1990.

GÓMEZ, Alemany I. Bases teóricas de una propuesta didáctica para favorecer la comunicación en el aula. En: Hablary escribir para aprender. Uso de la lengua en situación de enseñanzaaprendizaje desde las áreas curriculares. Barcelona, España: Editorial Síntesis. 2000.

GRUNDY, Shirley. Producto o praxis del currículum. Madrid: Ediciones Morata 1991. Traducción de Pablo Manzano. 1994.

HABERMAS, J. Teoría de la acción comunicativa: complementos y estudios previos. México: Ed. Rei. 1993.

LISTON, D. y ZEICHNER, K. Formación del profesorado y condiciones sociales de escolarización. Madrid: Morata. 1993.

MACCHIAROLA, Viviana; MORALES, Gladys; NICOLETTI, Silvia; VOGLIOTTI, Ana. La compleja vinculación teoría-práctica en tendencias de formación docente. Secyt. UNRC.

MALLART, Juan. Didáctica: concepto, objeto y finalidad. 2000.

MARHUENDA, F. Didáctica general. Madrid: Ediciones de la Torre. 2000.

MENA MERCHAN, B.; MARCOS PORRAS, M.; MENA MARCOS, J. J. Didáctica y nuevas tecnologías en educación. Madrid: Ed. Escuela Española. 1996.

NERICI, I. G. Hacia una didáctica general dinámica. 10. a edición. Buenos Aires (Argentina): Ed. Kapelusz. 1973. 
OSORIO SIERRA, J. M. Los indicadores de rendimiento en la evaluación institucional universitaria. Zaragoza: Ed. Instituto de Ciencias de la Educación de la Universidad de Zaragoza. 1995.

PERALES PALACIOS, F. J. La evaluación en la didáctica de las ciencias. Revista Interuniversitaria de Formación del Profesorado. nro. 27. 1996.

SADOUN, F.; SCHMIDT, V.; SCHULTZ, F. En: Les boutiques d'enfants de Berlin, Maspero, colección Textes a l'APPUI. París 1972. Subtitulado: Educación antiautoritaria y lucha por el socialismo.

SAVATER, F. El Valor de Educar. 3. a edición. Barcelona: Ed. Ariel. 1997.

SCHÖN, Donald. La formación de profesionales reflexivos. Hacia un nuevo diseño de la enseñanza y el aprendizaje en las profesiones. Barcelona: Paidós. MEC. 1987.

TALÍZINA, N. F. Conferencias sobre «Los fundamentos de la enseñanza en la educación superior». La Habana: Universidad de La Habana. 1984.

ZABALZA BERAZA, Miguel Ángel. Fundamentación de la didáctica y del conocimiento didáctico. En: MEDINA, A; SEVILLANO, M.L. (coordinadores): Didáctica-Adaptación, vol. 1, Madrid: UNED. 1990.

ZABALZA BERAZA, Miguel Ángel. Competencias docentes del profesorado universitario. Calidad y desarrollo profesional. Madrid: Narcea S. A. Ediciones. 2007. 